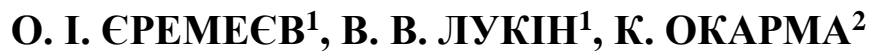

\author{
${ }^{1}$ Національний аерокосмічний університет ім. М. С. Жуковського \\ "Харківський авіаційний інститут», Украӥна \\ 2 Західо-Поморський технологічний університет, Щецін, Польща
}

\section{КОМБІНОВАНА МЕТРИКА ВІЗУАЛЬНОЇ ЯКОСТІ ЗОБРАЖЕНЬ ДИСТАНЦИЙНОГО ЗОНДУВАННЯ НА ОСНОВІ НЕЙРОННОЇ МЕРЕЖІ}

\begin{abstract}
Широке застосування зображень дистаниійного зондування (ДЗ) Землі в різних прикладних областях робить актуальним завдання забезпечення високої якості таких зображень, щзо є необхідним для видобування необхідної інформації. Складність систем та вплив різноманітних фізичних процесів зумовлюють наявність значної кількості завад, що призводять до спотворення зображень та можливої втрати інформації. Застосування методів обробки, щэо мають знизити вплив таких чинників, вимагає контролю їх роботи, для чого використовують кількісні показники візуальної якості. В статті розглядається завдання створення комбінованої метрики візуальної якості на основі штучної нейронної мережі (ШНМ), щзо має забезпечити високу точність оцінювання візуальної якості та стабільність роботи в умовах впливу завад, характерних для ДЗ. Розглянуто проблему аналізу завад ДЗ та запропоновано підхід до використання бази тестових зображень ТID2013 для верифікаиії для спотворень, щуо є типовими для зображень ДЗ. Проведено аналіз сучасних метрик візуальної якості та їх придатності для оичінки таких зображень. За його результатами визначено, щзо кращі метрики забезпечують адекватність оцінки якості для задач ДЗ на рівні 0,93 за ранговою корелящієє Спірмена з суб'єктивними оцінками для бази TID2013. Спільне застосування існуючих метрик якості дозволяє нівелювати недоліки кожної з них $i$ підвищити загальну ефективність, тому в статті розглянуто проблеми та визначено вимоги щзодо створення комбінованої метрики із залученням нейронної мережі. Запропоновано метод обмеження кількості задіяних метрик якості з залученням регуляризації Lasso, щуо дозволяє визначити найбільш інформативні ознаки (метрики якості) та спростити процедуру вибору $і$ зменшення їх кількості. Проведено дослідження щзодо впливу критерію вибору метрик та їх кількості на характеристики роботи комбінованої метрики. Також проаналізовано вплив структури нейронної мережі, кількості прихованих шарів та кількості нейронів в них. На основі отриманих результатів обрано найкращу реалізацію ШНМ, яка при залученні 16 елементарних метрик візуальної якості дозволяє досягати значень 0,97 за кореляијєєю Спірмена з суб 'єктивними очінками бази TID2013.
\end{abstract}

Ключові слова: метрика візуальної якості; нейронна мережа; обробка зображень; оцінка візуальної якості зображень; база зображень.

\section{Вступ}

Дистанційне зондування (ДЗ) Землі є одним 3 ключових напрямків використання цифрових зображень. Унікальні можливості, що надаються даними системами, сприяють їх великій кількості та розмаїттю $[1,2]$. Різні за своєю природою системи формування зображень дозволяють різнобічно вивчати явища та процеси, зокрема для великих територій, їx зміни та розвиток. Завдяки сучасній тенденції отримання багатоканальних зображень [3-5] та їх попередній обробці [1], дані Д3 можуть бути покращені, потім їх піддають подальшому аналізу та обробці.

Методи обробки зазвичай дозволяють виправити певні недоліки отриманих даних, але здебільшого цього може бути недостатньо. Існує значна кількість факторів, які впливають на якість зображення та наявну інформацію і заважають вирішувати різні завдання обробки даних ДЗ, зокрема значна хмарність у випадку оптичних та інфрачервоних зображень [6]. Та найбільш розповсюдженим негативним чинником $€$ шум різного походження та типу [4-6]. Зниження якості зображення може також відбуватися внаслідок використання методів обробки, якщо їх застосування є надлишковим чи неспівмірним з вимогами та особливостями даних [5]. У зв'язку з тим, що формування зображення є багатоетапним процесом, на практиці спотворення мають множинний характер зі значною варіативністю інтенсивності кожної складової. Прикладом можуть бути зображення, що водночас спотворені дефокусуванням та шумом або зображення з шумом, що стиснені з втратами [7]. Досить розповсюдженими є ситуації гіперспектральних зображень 3 компонентами як високої так і досить низької якості [8] або зображення радіолокатора iз синтетичною апертурою (РСА), для яких завжди присутній спекл-шум [4, 9]. 
Враховуючи великий об'єм даних дистанційного зондування і потребу в автоматизації обробки, доцільним $є$ контроль за допомогою певних кількісних показників як якості первинних зображень, так і змін, що вносяться в них під час обробки. Серед таких об'єктивних методів оцінки візуальної якості вирізняють декілька класів показників (метрик якості), які можна класифікувати в залежності від наявності оригінального зображення [10]. Метрики якості з еталоном застосовуються в таких задачах, як стиснення даних зі втратами, де зміна візуальної якості обчислюється використовуючи первинні та спотворені зображення. У випадку, коли присутне тільки спотворене зображення, можуть бути використані метрики без еталону, для яких кількісні показники обчислюються на основі характеристик самого зображення.

В статті увага зосереджена на еталонних метриках, що характеризують візуальну якість оригінальних зображень або зображень після проведеної обробки, наприклад, як фільтрація чи стиснення 3 втратами. Звичайні метрики, такі як середньоквадратична похибка (mean square error, MSE) або пікове співвідношення сигнал/шум (peak signal to noise ratio, PSNR), все ще широко використовуються для аналізу зображень ДЗ або оцінки ефективності їх обробки [11] Втім, існує очевидна тенденція застосовувати візуальні показники якості [12-14]. Однак кількість робіт, де використовуються показники візуальної якості, все ще є обмеженою [12-15].

\section{1. Проблеми метрик візуальної якості}

Застосування метрик візуальної якості надає ряд суттєвих переваг при проведенні аналізу та обробки зображень. Дані показники обчислюють візуальну якість зображення, використовуючи певні моделі системи людського зору (human visual system, HVS) $[10,16]$. Їх врахування в завданнях обробки зображень, таких як придушення шуму, стиснення з втратами, виявлення меж, сегментація та класифікація, дозволяє забезпечити результати, наближені до суб'єктивних оцінок людини. Це надає можливість підвищити ефективність обробки і автоматизувати цей процес.

На даний момент жодна метрика не є повністю універсальною. Тому в залежності від завдання, особливостей системи формування зображень, типових негативних чинників, необхідно розуміти, які метрики можна застосовувати і якою $є$ їх ефективність. Подібні проблеми частково вирішені в мультимедійних додатках, в яких верифікація метрик якості за допомогою спеціальних баз тестових зображень $[10,16$ 19] є загальноприйнятим підходом (рис. 1). Бази відрізняються за кількістю зображень та врахованих спотворень, але загальним є те, що для всіх тестових зображень в результаті проведення експериментів 3 залученням людей, формується суб'єктивна оцінка якості (mean opinion score, MOS). Точність метрик якості визначається в результаті кореляційного аналізу з використанням коефіцієнту кореляції Пірсона (Pearson correlation coefficient, PCC) та/або рангового коефіцієнту кореляції Спірмена (Spearman rank order correlation coefficient, SROCC).

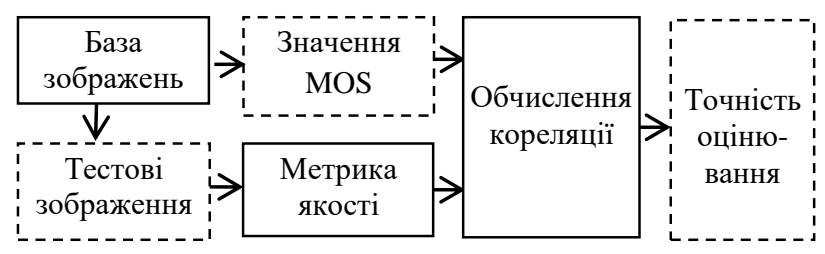

Рис. 1. Схема верифікації метрик візуальної якості

На даний час для найбільших баз тестових зображень, таких як TID2013 [17], точність елементарних метрик якості з еталоном не перевищує 0,9 , що є недостатнім. Для вирішення даної проблеми науковцями висунуто шляхи підвищення ефективності метрик, включаючи проектування комбінованих метрик [20, 21] або метрик на основі ШНМ, деякі приклади яких наведені в $[22,23]$.

Потенціал використання метрик візуальної якості й досі не використано в завданнях ДЗ. На це є декілька причин. По-перше, відсутні спеціальні бази зображень Д3, які можна використовувати для оцінки показників якості. По-друге, у формуванні MOS зазвичай приймають участь різні люди (не професіонали), що оцінюють кольорові та напівтонові зображення. Врахування думок будь-яких споживачів важливе, і вони обробляються у надійний спосіб $[16,17]$. Ситуація з зображеннями ДЗ інша - кількість каналів може складати десятки 3 суттєвою відмінністю інформаційної складової, а це може вплинути на їх візуальне сприйняття. Також важко знайти багато людей, навчених аналізувати та класифікувати зображення Д3, пропонуючи свої думки щодо якості зображення (проведення ранжування зображень). Ці фактори обмежують дослідження, спрямовані на проектування візуальних метрик та верифікацію зображень для ДЗ.

Проте, на наш погляд, можна провести попередній аналіз придатності метрик для оцінювання візуальної якості зображень ДЗ. Необхідною вимогою для цього є застосування баз тестових зображень зі спотвореннями, що є типовими для зображень ДЗ у різних застосуваннях. Серед існуючих баз даних варто відмітити TID2013 [17], яка містить практично всі основні типи завад і спотворень, що характерні для ДЗ. Інше можливе обмеження застосування метрик полягає в тому, що аналіз зображень ДЗ значною мірою 
відрізняється від аналізу кольорових зображень. Хоча слід зауважити, що частиною систем ДЗ є системи аерофотозйомки та системи безпілотних літальних апаратів (БПЛА), що формують зображення оптичного діапазону. Дослідження для цього окремого випадку можуть мати два ключових наслідки - оцінити ефективність застосування відомих показників якості для оптичних зображень ДЗ та актуальність їх розробки і використання для завдань ДЗ в цілому.

\section{2. Аналіз ефективності метрик візуальної якості}

При розробці та удосконаленні метрик візуальної якості до них висувають певну низку вимог, яким вони мають задовольняти і частково можливість їх реалізувати визначається вибором баз тестових зображень, наприклад:

- хороша точність оцінювання якості зображень, що підтверджується високими значення коефіцієнта кореляції між метрикою та MOS;

- створення універсальної метрики, здатної добре працювати при численних та різних типах спотворень потребує універсальних баз даних, що містять значну кількість різних типів спотворень;

- висока швидкодія, ефективні алгоритми обчислення зображень з високою роздільною здатністю;

- монотонність метрики та чітка відповідність величини метрики до візуальної якості.

Вибір бази TID2013 зумовлений тим, що вона $\epsilon$ однією 3 найбільших баз тестових зображень і містить 25 кольорових зображень, які спотворені 24 типами завад по п'ять рівнів інтенсивності, загалом кількістю у 3000 тестових зображень. Переважна більшість завад є типовими для багатоканальних зображень [24], та детально розглянуті в [17], як і їх групування в певні множини згідно з особливостями.

В даний час існує велика кількість візуальних показників якості, що розроблялися на протязі декількох десятиліть. Частину з них можна розглядати як модифікації PSNR (наприклад, PSNR-HVS-M [25]) або модифікації SSIM (наприклад, MS-SSIM [25]). Решта метрик були розроблені на основі інших принципів. Показники значно відрізняються і шкалою виміру, наприклад, деякі показники виражаються в дБ і варіюються в широких межах, тоді як інші обмежені в діапазоні від 0 до 1. При обчисленні та використанні метрик слід враховувати, що деякі з них можуть оцінювати похибку, і тоді їх меншим значенням відповідатиме краща візуальна якість, прикладом є метрика DCTune [25]. Ще одним важливим фактором застосування метрик якості $є$ те, що деякі з них розроблені для оцінки зображень у відтінках сірого, а для кольорових зображень їх значення зазвичай обчис- люється як середнє значення покомпонентного обчислення.

Значення SROCC для п'ятдесяти метрик візуальної якості, посилання на які вказано у [25], представлені в таблиці 1 для всіх типів спотворень, а також для підмножин "Noise", "Actual" та "Noise\&Actual", що включає зображення з усіма типами спотворень обох підмножин, загалом 13 типів завад і спотворень.

3 результатів можна виділити, що існує кілька досить універсальних показників (MDSI, PSIM, VSI), для яких SROCC майже досягає 0,9. Значення SROCC для підмножин є більшими, ніж для всіх типів спотворень. Найкращий результат для підмножини "Noise" забезпечує MDSI (SROCC $=0,928)$, тоді як для підмножини “Actual” (SROCC $=0,939)$ найбільші значення забезпечуються кількома показниками (MDSI, PSNRHA, PSNRHMAm); для обох підмножин разом найбільший SROCC у 0,937 надається MDSI. Такі результати можна вважати задовільними для багатьох практичних застосувань, що не виходять за межі вказаних типів спотворень. Але подальше поліпшення отриманих значень SROCC теж залишається затребуваним.

\section{3. Вимоги до комбінованої метрики}

В останні роки штучні нейронні мережі набувають розповсюдження і демонструють високий потенціал у вирішенні багатьох задач, пов'язаних з обробкою зображень [22, 26,27]. Використання ШНМ часто розглядається як шлях до отримання переваг при проектуванні та поліпшенні ефективності, що забезпечується встановленням ними явних та прихованих взаємозв'язків між різними факторами та отриманні більш точного результату. Відповідно нейронні мережі також можуть бути залучені при розробці комбінованої метрики якості для забезпечення більшої адекватності оцінювання візуальної якості.

Метрика на основі ШНМ повинна забезпечити кращий результат, аніж окремі (елементарні) метрики. Так, порівняно з досягнутими вже значеннями в $0,93 \ldots 0,94$ для "Noise\&Actual”, покращення на 0,02...0,03 можна вважати достатнім. Ефективність нейронної мережі значною мірою залежить від таких важливих аспектів, як вхідні параметри та структура. Розглядаючи можливість комбінування метрик на основі ШНМ, слід виділити в якості однієї з типових вимог високу швидкість обчислення метрик з еталоном, тому вхідні параметри не мають бути надто складними. Аналогічно слід враховувати можливість спрощення мережі без значної втрати ефективності за рахунок меншої кількості прихованих шарів і нейронів в них. Мінімально-достатня кількість вхідних параметрів також $є$ бажаною. 
Таблиця 1

Значення коефіцієнтів рангової кореляції Спірмена для всіх типів спотворень і для обраних підмножин TID2013

\begin{tabular}{|c|c|c|c|c|c|c|c|c|c|c|c|}
\hline № & $\begin{array}{c}\text { Метрики } \\
\text { візуальної } \\
\text { якості }\end{array}$ & $\begin{array}{c}\text { Всі } \\
\text { завади } \\
\text { TID2013 }\end{array}$ & Noise & Actual & $\begin{array}{l}\text { Noise\& } \\
\text { Actual }\end{array}$ & № & $\begin{array}{c}\text { Метрики } \\
\text { візуальної } \\
\text { якості }\end{array}$ & $\begin{array}{c}\text { Всі } \\
\text { завади } \\
\text { TID2013 }\end{array}$ & Noise & Actual & $\begin{array}{l}\text { Noise\& } \\
\text { Actual }\end{array}$ \\
\hline 1 & MDS & 0,8897 & 0,9275 & 0,9387 & 0,9374 & 26 & IWSSIM & 0,7775 & 0,8783 & 0,8934 & 0,8937 \\
\hline 2 & & 0,8090 & 0,9248 & 0,9350 & 9341 & 27 & & 0,7657 & 0,8743 & 0,8887 & 8,8902 \\
\hline 3 & MCSD & 0,8045 & 0,9224 & 0,9326 & & 28 & & 8417 & 0,8728 & 0,8878 &, 8892 \\
\hline 4 & PSNR & 0,8198 & 0,9230 & 0,9388 & & 29 & & $\overline{7872}$ & 0,8733 & & 8881 \\
\hline 5 & $\bar{D}$ & 0,8004 & 11 & 0,93 & & 30 & & & 0,87 & 0,8793 & 8847 \\
\hline 6 & $\begin{array}{l}\text { PSNRI } \\
\end{array}$ & & & $\overline{0}$, & & 31 & & 6809 & 0,8691 & & \\
\hline 7 & PSIM & 0,8926 & 0,9189 & 0,9309 & & 32 & & 21 & 0,8411 & 0,8866 & \\
\hline 8 & NRHI & 7794 & 0,9184 & 0,9272 & 0,9275 & 33 & CSSIM4 & 0,7394 & 0,8432 & 0,8668 & 8604 \\
\hline 9 & NRHVS & 0,6536 & 0,9172 & 0,9257 & 9263 & 34 & GSM & 0,8028 & 0,8408 & 0,8841 & $\overline{8,8583}$ \\
\hline 10 & PSNRHMA & 0,8137 & 0,9151 & 0,9343 & 0,9250 & 35 & VI & 0,6816 & 0,8422 & 0,8585 & 0,8532 \\
\hline 11 & IGM & 0,8023 & 0,9099 & 0,9220 & 0,9227 & 36 & NQM & 0,6349 & 0,8362 & 0,8572 & 0,8527 \\
\hline 12 & SNRHMAy & 0,7570 & 0,9107 & 0,9209 & 0,9226 & 37 & $\overline{\mathrm{RV}}$ & 0,6748 & 0,8192 & 0,8449 & 0,8423 \\
\hline 13 & VSI & 0,8967 & 0,9101 & 0,9258 & 0,9218 & 38 & & 0,6396 & 0,8217 & 0,8246 & 0,8335 \\
\hline 14 & SR-SIM & 0,8076 & 0,9070 & 0,9211 & 0,9206 & 39 & PSNR & 0,6396 & 0,8217 & 0,8246 & 0,8335 \\
\hline 15 & HaarPSI & 0,8730 & 0,9063 & 0,9168 & 0,9190 & 40 & MSUNIQUE & 0,7521 & 0,7981 & 0,8276 & 0,8247 \\
\hline 16 & ADM & 0,7861 & 0,9113 & 0,9201 & 0,9189 & 41 & UNIQUE & 0,7466 & 0,7829 & 0,8157 & 0,8117 \\
\hline 17 & PSNRHVSM & 0,6246 & 0,9061 & 0,9175 & 0,9188 & 42 & VIFP & 0,6084 & 0,7835 & 0,8151 & 0,8056 \\
\hline 18 & FSIMc & 0,8510 & 0,9022 & 0,9150 & 0,9164 & 43 & CWSSIM & 0,5551 & 0,7943 & 0,8160 & 0,8051 \\
\hline 19 & ADD_GSIM & 0,8310 & 0,9023 & 0,9151 & 0,9159 & 44 & & 0,7114 & 0,7493 & 0,7801 & 0,7838 \\
\hline 20 & IQM2 & 0,7955 & 0,8995 & 0,9103 & 0,9 & 45 & SSI & 0,6371 & 0,7574 & 0,7877 & 0,7812 \\
\hline 21 & ADD_SSII & 0,8023 & 0,9008 & 0,91 & & 46 & & 0,5229 & 0,7201 & 0,7598 & 0,7468 \\
\hline 22 & & 0,8011 & 0,8969 & 0,9108 & & 47 & & 0,5975 & 0,6604 & 0,6948 & $\overline{0,7049}$ \\
\hline 23 & $\overline{\text { WSNR }}$ & 0,5796 & 0,8804 & 0,8966 & & \begin{tabular}{|l|}
48 \\
\end{tabular} & & 0,5444 & 0,6482 & 0,6904 & 0,6824 \\
\hline 24 & & 0,8518 & 0,8787 & 0,9059 & 0,8946 & 49 & & 0,2903 & 0,3290 & 0,4173 & 0,3139 \\
\hline & DSS & 0,7915 & 0,8766 & 0,8904 & 0,8945 & 50 & MSVD & 0,1261 & 0,1123 & 0,1309 & 0,1424 \\
\hline
\end{tabular}

Враховуючи зазначене, ідея дослідження полягає у використанні наборів окремих еталонних метрик $з$ еталоном як вхідних даних ШНМ досить простої структури для вирішення проблеми отримання комбінованої метрики (або декількох комбінованих метрик) з точністю, вищою за результати кращих метрик.

Подальше дослідження буде проводитись 3 використанням бази TID2013, бо вона відповідає вимогам щодо переліку типів завад, можливостей навчання ШНМ та верифікації результатів. Розглядаючи можливі варіанти визначення виходу ШНМ, необхідно враховувати, що результат комбінованої метрики має бути пропорційним до візуальної якості зображення і інтуїтивно зрозумілим. Визначення виходу ШНМ в межах MOS для TID2013 з одного боку є достатньо наглядним, а 3 іншого може бути використана мінімізація помилок щодо MOS як цільова функція у навчанні нейронної мережі на цій базі. За потреби значення виходу ШНМ можуть бути легко перераховані до іншого масштабу, наприклад, від 0 до 1.
Комбінована метрика якості, що розробляється, передбачає використання елементарних метрик як вхідних даних нейронної мережі. Незважаючи на нелінійність і значну розбіжність в діапазонах виміру величин метрик візуальної якості, для нейронних мереж це не проблемою, оскільки сігмоїдна функція активації забезпечує нормалізацію до проміжку $-1 . . .1$.

Наступним питанням слід розглянути які структури та параметри ШНМ можуть бути обрані та оптимізовані. Вибір багатошарових мереж з урахуванням їх особливостей дозволяє зменшити складність нейронної моделі у відповідності до існуючих даних, добре узагальнити створену модель та запобігти проблемам перенавчання. Так, кількість нейронів у вхідному шарі має бути рівною кількості елементарних метрик, що використовуються. Можливі різні варіанти визначення кількості метрик, включаючи використання усіх 50 елементарних метрик. Іншим можливим підходом може бути обмеження найкращими метриками з таблиці 1 за певними критеріями, напри- 
клад, метрики, для яких для розглянутих типів спотворень SROCC > 0,9 (22 метрики), $\mathrm{SROCC}>0,92$ (14 метрики) або SROCC > 0,93 (7 метрик).

Відповідно до теорії нейронних мереж, доцільно обирати і застосовувати вхідні параметри, які надають нову “унікальну” інформацію відносно один до одного, тобто мають не занадто високу кореляцію. Одним із шляхів знаходження інформативних ознак $\epsilon$ оцінка функції взаємної кореляції, що визначає подібність між усіма парами метрик. Згідно з нею покроково у всіх висококорельованих парах слід виключити найгірші метрики. В даній роботі замість цього підходу вибір унікальних метрик для нейронної мережі пропонується за результатами регуляції Lasso [28] (Lasso або Least absolute shrinkage and selection operator - оператор найменшої абсолютної усадки та вибору). При машинному навчанні регуляризації Lasso та Ріджа використовуються для введення додаткових обмежень у модель та зменшення проблеми перенавчання. Ключовою особливістю методу Lasso $\epsilon$ те, що він для “шумних” та найменш важливих даних може призначати нульові ваги, виводячи їх з подальшого аналізу. Для комбінованої метрики це означає можливість виключення метрик якості, що в меншій мірі $є$ корисними для комбінування. Тобто, в даному сенсі застосування метода можна розглядати як альтернативу багатоетапному підходу визначення взаємної кореляції. Реалізація Lasso в програмному забезпеченні MATLAB дозволяє на визначеному діапазоні порогових значень параметру $\alpha$ (від 0 до 100) визначити коефіцієнти для кожної $з$ елементарних метрик. I чим менше користі від метрики якості, тим більшу кількість нулів вона отримає для різних порогових значень. Такий підхід можна застосувати для попереднього визначення і виключення метрик візуальної якості з набору вхідних даних для нейронної мережі. Відповідно до цього було визначено кількість таких ненульових значень $\mathrm{N}$ для кожної метрики, приймаючи такі умови: а) $\mathrm{N}>20$ (зі 100 значень); б) $\mathrm{N}>30$; в) $\mathrm{N}>40$; г) $\mathrm{N}>50$; д) $\mathrm{N}>60$.

Структура та кількість елементів нейронної мережі безпосередньо впливають на ефективність навченої мережі. Крайні шари мають залежати від параметрів вхідних та вихідних даних. Оскільки вихід мережі є комбінованою метрикою, то у вихідному шарі присутній один нейрон, а а кількість вхідних ві- дповідає кількості елементарних метрик, що використовують. Крім того, необхідно визначити оптимальну кількість шарів та нейронів в кожному 3 них, оскільки $з$ одного боку завелике їх значення може призводити до перенавчання і некоректної роботи мережі, зниження іiї швидкодії. 3 іншого, замале значення нейронів буде причиною падіння точності роботи комбінованої метрики. Кількість прихованих шарів і кількість нейронів у кожному прихованому шарі можуть бути різними. Було проаналізовано два варіанти - два та три прихованих шари. Для кожного 3 них обрано два варіанти кількості нейронів у прихованих шарах: а) однакова кількість нейронів у кожному прихованому шарі та б) зменшення приблизно вдвічі кількості нейронів у кожному наступному прихованому шарі для рівномірного зменшення до одного нейрона для вихідного шару.

Як функція активації у прихованих шарах використовується гіперболічна дотична сигмоїдна передавальна функція, властивістю якої також є нормалізація значень в діапазоні від -1 до 1. Лінійна функція використовується для вихідного шару та забезпечення результатів, сумісних з MOS.

Приклад структури ШНМ представлено на рис. 2 для випадку, коли визначено 9 входів, а кількість нейронів у прихованих шарах поступово зменшується до одного.

Основним етапом створення нейронної мережі $€$ iï навчання. Дана процедура передбачає поділ вхідних даних на два набори - навчальний та тестовий. При навчанні ШНМ оптимізує ваги кожного нейрону таким чином, щоб результат навчання максимально точно відповідав вихідним даним, тобто MOS. Пари вхідних даних та MOS забезпечують верифікацію. При формуванні було задіяно випадковий розподіл, за яким 70\% зображень (і відповідно отриманих для них значень метрик якості) було використано для навчання, а решту зображень для перевірки.

Варто відмітити особливості даних TID2013, що певною мірою впливають на результат. Чим більший обсяг даних, тим точніше результат навчання і зменшується вірогідність перенавчання. TID2013 забезпечує чи не найкращий перелік спотворень для задач Д3, але для кожного еталонного зображення передбачено 5 рівнів спотворень певним типом завад.

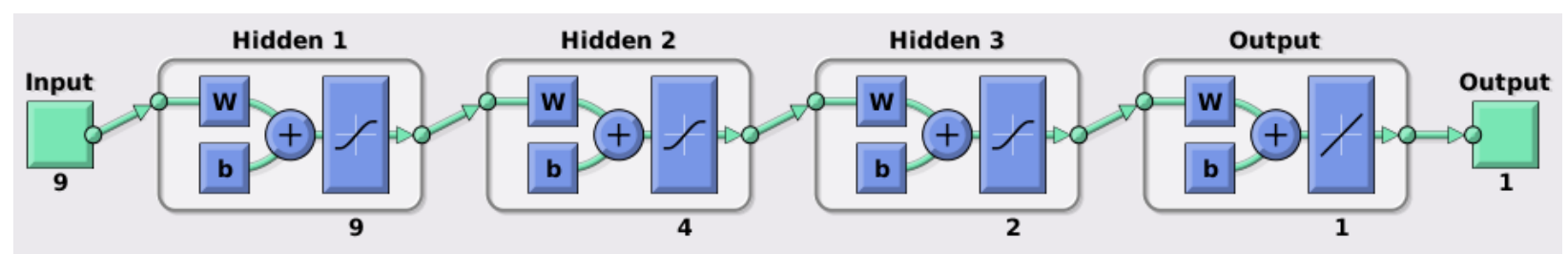

Рис. 2. Приклад структури багатошарової нейронної мережі з 9 вхідними даними (елементарні метрики якості) та змінною кількістю нейронів у шарі 
В результаті стоїть питання, як їх коректно поділити на навчальний і тестовий набір для забезпечення точного результату, так як фіксований варіант має ризики неефективного навчання. Для забезпечення стабільності результатів навчання при обмеженому наборі з 1625 зображень обрано випадковий розподіл зображень на набори, результати навчання та перевірки якого будуть давати значення оптимізованих випадкових комбінацій. Щоб частково обійти цю невизначеність і наблизитися до глобального максимуму функції для кожної конфігурації було проведене не менше 20 навчань, найкращі результати яких у подальшому розглядаються нижче для кожної версії навченої ШНМ за показником SROCC. Кількість вхідних метрик для кожного з визначених критеріїв наведено в табл. 2.

Таблиця 2

Кількість вхідних даних нейронних мереж, що обрано відповідно до критеріїв їх вибору

\begin{tabular}{|c|c|}
\hline $\begin{array}{c}\text { Критерії попереднього } \\
\text { вибору метрик }\end{array}$ & $\begin{array}{c}\text { Кількість метрик } \\
\text { якості }\end{array}$ \\
\hline Bсі 50 метрик & 50 \\
\hline 3начення SROCC $>0,8$ & 43 \\
\hline 3начення SROCC $>0,9$ & 22 \\
\hline 3начення SROCC $>0,92$ & 14 \\
\hline 3начення SROCC $>0,93$ & 7 \\
\hline Lasso 3 N $>20$ & 43 \\
\hline Lasso 3 N $>30$ & 38 \\
\hline Lasso 3 N $>40$ & 24 \\
\hline Lasso 3 N $>50$ & 16 \\
\hline Lasso 3 N $>60$ & 11 \\
\hline Lasso 3 N $>70$ & 7 \\
\hline
\end{tabular}

\section{4. Навчання та верифікація нейронних мереж}

Основними критеріями точності навчання та перевірки ШНМ відносно значень MOS є коефіцієнти кореляції Спірмена. Можна виділити результати SROCC для чотирьох груп вхідних даних: Train (Max) - SROCC навчального набору метрик вище певних порогових значень SROCC, Train (Lasso) - SROCC навчального набору значень за методом Lasso, Test (Max) i Test (Lasso) - відповідні тестові набори. Отримані результати представлені на рисунку 3. Цифри на представлених графіках біля кожної точки показують кількість нейронів у прихованих шарах. Дані на рис. 3,а наведені для випадку, коли кількість нейронів у прихованих шарах однакова, на рис. 3,б вони відповідають ситуації, коли кількість нейронів в наступному шарі зменшується.

Аналіз даних показує наступне:

- для випадку вибору вхідних метрик вище порогового значення SROCC є загальна тенденція збільшення SROCC Train(max) i Test(max) від кількості метрик; після кількості у 40 входів покращення припиняється і спостерігається деякий спад точності;

- для регуляції Lasso характерна суттєва залежність точності нейронної мережі від кількості елементарних метрик, якщо їх менше 11, з більш пологим ростом до 20 і практично не залежить при подальшому збільшенні кількості вхідних даних; в усіх випадках результат перевищує інший підхід вибору метрик, це означає, що метод Lasso дозволяє спростити структуру ШНМ, мінімізуючи кількість входів та нейронів в інших шарах і тим самим підтверджуючи припущення, що такий підхід дозволить виділити найбільш значущі метрики візуальної якості;

- найкращі (найбільші) значення SROCC для комбінованої метрик на основі ШНМ перевищують 0,97, що демонструє достатнє покращення порівняно 3 найкращими елементарними метриками;

- SROCC (train) та SROCC (test) практично не відрізняються для всіх зображених конфігурацій ШНМ, тому результати навчання можна вважати стабільними;

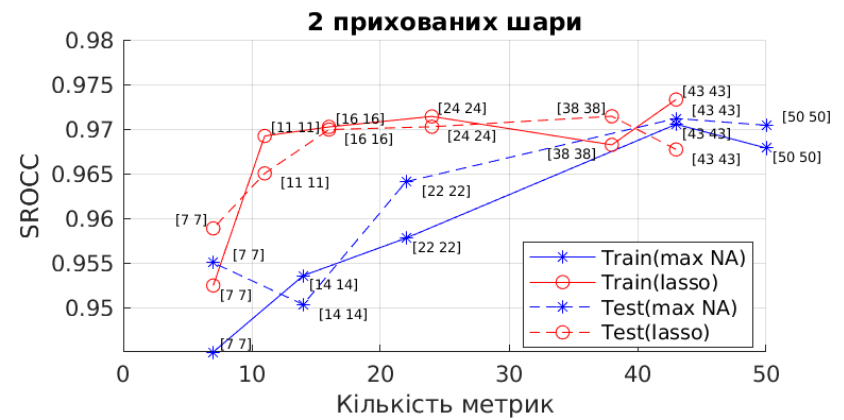

a

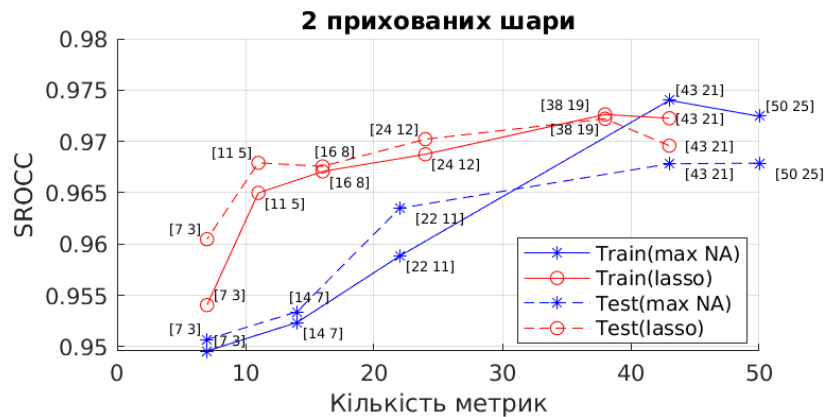

б

Рис. 3. Значення кореляції Спірмена для ШНМ з двома прихованими шарами та різною кількістю вхідних даних: а - однакова кількість нейронів у кожному шарі;

б - вдвічі менша кількість нейронів у наступному шарі 
- для двошарової нейронної мережі використання рівної або нерівної кількості нейронів у прихованих шарах має різницю в результатах ефективності, у зв'язку з чим можна визначити, що складності мережі зі зменшенням нейронів недостатньо для вхідних даних.

Вплив структури більш складної моделі показано на рис. 4 для прикладу з трьох прихованих шарів. Аналіз нових даних дозволяє доповнити попередні результати і зробити два основні висновки. По-перше, немає очевидних переваг даної моделі у порівнянні 3 випадком використання ШНМ з двома прихованими шарами. По-друге, всі попередні висновки щодо SROCC (train) та SROCC (test), впливу регуляризації Lasso та кількості вхідних даних однакові. Тобто можна зробити висновок, що доцільно застосовувати метод Lasso , а враховуючи, що метою створення комбінованої метрики є забезпечення високих значень SROCC, то кількість елементарних метрик варто обмежити на рівні 24.

Підводячи підсумки аналізу залежності ефективності комбінованої метрики в залежності від структури ШНМ, можна констатувати наступне:

- різні конфігурації ШНМ з оптимальними наборами параметрів забезпечують приблизно однаковий SROCC;

- орієнтуючись на зниження складності без зниження точності, рекомендується використовувати ШНМ з двома прихованими шарами і рівною кількістю нейронів, без попереднього фітингу та з числом входів близько 20.

В попередньому узагальненому аналізі не розглядалися два інші аспекти - які елементарні метрики обираються при застосуванні Lasso , і як висновки, зроблені в результаті аналізу SROCC, узгоджуються з результатами за іншими критеріями. Відповідно до першого питання, дві хороші конфігурації ШНМ на рис. 3,а складаються 316 та 24 входів. В ШНМ 316 входами використовуються наступні елементарні метрики: PSNR, IFC, MSVD, PSNRHVS, CWSSIM, RFSIM, PSNRHA, ADM, IGM, GMSD, WASH, IQM2,
MDSI, CVSSI, DSI, НаarPSI. Нейронній мережі з 24 входами відповідають показники візуальної якості PSNR, MSE, NQM, MSSIM, IFC, VIF, MSVD, QILV, PSNRHVS, CWSSIM, RFSIM, PSNRHA, ADM, IGM, GMSD, WASH, IQM2, DSS, MDSI, MSUNIQUE, CVSSI, DSI, CSSIM4 і HaarPSI. Можна побачити, що всі 16 показників з першого набору також присутні у другому наборі.

Розглядаючи метрики варто відмітити, що метрики MDSI, CVSSI, PSNRHA, GMSD, IGM, HaarPSI, ADM, IQM2 серед обраних входять до топ-20 у таблиці 1. Також були обрані деякі помірно хороші показники, такі як DSS. С елементарні метрики, які ефективні згідно з даними таблиці 1, але вони не були обрані, наприклад, MCSD, PSNRHMAm, PSIM. Для PSNRHMAm причиною виключення метрики Lasso може бути iі висока кореляція 3 PSNRHVS та PSNRHA, але ситуація не $\epsilon$ настільки однозначною для MCSD та PSIM. Тим часом набори містять такі метрики, як WASH та MSVD, які, згідно з даними таблиці 1, не мають належної ефективності. Обидва набори містять PSNR, а другий набір також містить MSE, цілком пов'язаний з PSNR, тут можливим $є$ нелінійний зв'язок даних показників. Хоча в цілому варто відмітити, що Lasso дозволяє звужувати набори рекомендованих елементарних метрик, але результат його роботи може мати певні обмеження.

Тим не менше, регуляризація Lasso надає декілька переваг при проектуванні ШНМ. I вони є очевидними виходячи 3 аналізу даних, представлених у таблиці 3. Так, можна помітити, що існує кілька хороших конфігурацій ШНM, які забезпечують SROCC на рівні 0,97 і вище для близько 20 вхідних метрик. Вказані ШНМ при цьому забезпечують значно менші значення RMSE, ніж для найкращої метрики, якщо проводити іiі лінеаризацію [20] (значення RMSE більше 0,39). Крім того, значення коефіцієнта кореляції Пірсона (РСС) також великі і перевищують 0,97, що свідчить про дуже хорошу властивість лінійності комбінованих метрик.

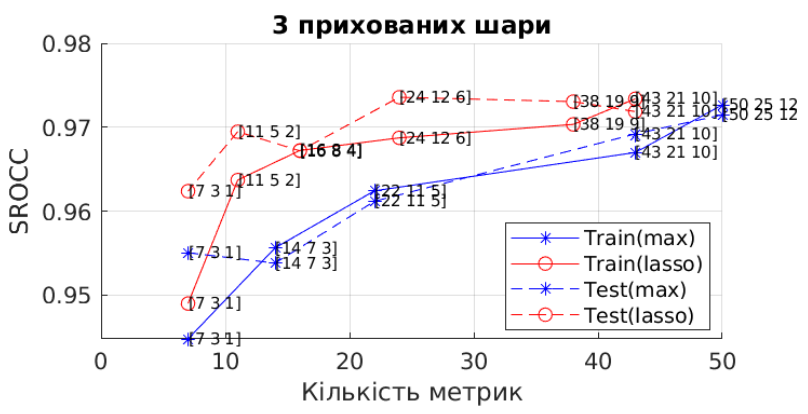

6

a

Рис. 4. Значення кореляції Спірмена для ШНМ з трьома прихованими шарами та різною кількістю вхідних даних: а - однакова кількість нейронів у кожному шарі; б - вдвічі менша кількість нейронів у наступному шарі 
Розрахувавши значення SROCC, RMSE та PCC, можна провести більш ретельний аналіз. Перше спостереження полягає в тому, що всі показники в нашому випадку мають високу кореляцію: більші коефіцієнти Спірмена і Пірсона відповідають меншим RMSE. Найкращі результати, згідно з усіма трьома критеріями, дає ШНМ 3 конфігурацією №3, хоча, враховуючи складність даної мережі (24 входів), конфігурація №2 варта уваги. Кількість входів менше 16 (наприклад, 11 або 12 у конфігурації №1) призводить до погіршення значень розглянутих критеріїв.

Використання конфігурацій нейронної мережі зі зменшенням кількості нейронів у прихованих шарах, більшою кількістю прихованих шарів (конфігурації №6-9) не дають покращень у порівнянні з відповідними конфігураціями №1 та №2. Враховуючи вищезазначене, використання конфігурації ШНМ №2 буде розглянуто більш детально.

Таблиця 3 містить стовпці, поєднані заголовком «Найкраща ШНМ», і стовпці, позначені «5 найкращих результатів». Раніше вже згадувалося, що результати навчання ШНМ залежать від випадкового розподілу спотворених зображень навчального та тестового наборів. Через це для аналізу стабільності навчання були обчислені середні значення показників SROCC, PCC та RMSE для п'яти найкращих результатів навчання ШНМ (з 20 проведених) для кожної конфігурації.

Порівняння перших п'яти результатів із відповідними найкращими значеннями для найкращої мережі показує, що різниця невелика. Більше того, висновки, які можна зробити в результаті аналізу усередненого значення 5 кращих мереж щодо результатів роботи ШНМ, повністю збігаються з висновками, зробленими в результаті аналізу найкращої мережі.

\section{Висновки}

Розглянуто завдання оцінки візуальної якості зображень дистанційного зондування, для яких спостерігається вплив різних типів завад. Показано, що загальновизнаних показників не існує, тому стоїть питання їх розробки. Зазначено проблеми, з якими можна зіткнутися, та запропоновано їх вирішення. Для цієї мети використана вже існуюча база даних спотворених кольорових зображень TID2013, для яких можна вибрати зображення із спотвореннями, що є типовими для дистанційного зондування. Ї̈̈ використання дозволяє визначити кращі з існуючих показників візуальної якості, що забезпечують SROCC 3 MOS близько 0,93. Це можна вважати хорошим результатом. Більше того, база даних TID2013 дозволяє розробляти показники візуальної якості на основі використання елементарних метрик якості зору як вхідних даних ШНМ. Показано, що навіть прості ШНМ без попередньої обробки вхідних даних, двома прихованими шарами, здатні забезпечити значення SROCC близько 0,97. Значення PCC мають той же порядок, що свідчить про практично лінійний зв'язок між виходом ШНМ та значеннями MOS.

Отримані результати підтверджують ефективність комбінованої метрики на основі нейронної мережі і можливість ії застосування для оцінки візуальної якості оптичних зображень в різних задачах ДЗ $з$ метою підвищення ефективності обробки зображень, iї автоматизації. Надалі є потреба у прискоренні метрики на основі ШНМ за допомогою обмеження набору можливих входів, враховуючи також обчислювальну ефективність вхідних метрик. Іншою актуальною задачею $є$ розширення області застосування розробленої метрики й на інші поширені типи зображень, зокрема багатоканальні зображення ДЗ.

Дослідження частково співфінансується Польським національним агентством з академічного обміну (NAWA) та Міністерством освіти і науки України за проектом № PPN / BUA / 2019/1/00074 (M/452020) під назвою „Методи інтелектуальної обробки зображень та відео на основі метрик візуальної якості для перспективних застосувань”.

\section{Література}

1. Schowengerdt, R. A. Remote sensing, models, and methods for image processing [Text] / R. A. Schowengerdt ; 3rd ed. - Burlington : Academic Press, 2007. $560 \mathrm{p}$.

2. Future Trends in Remote Sensing. In Principles of Applied Remote Sensing [Text] /S. Khorram, C. F. van der Wiele, F. H. Koch, S. A. C. Nelson, M. D. Potts. Springer International Publishing : Cham., 2016. P. 277-285.

3. A Review of the Application of Optical and Radar Remote Sensing Data Fusion to Land Use Mapping and Monitoring [Text] / N. Joshi, M. Baumann, A. Ehammer, R. Fensholt, K. Grogan; P. Hostert, et al. // Remote Sensing. - 2016. - Vol. 8, no. 1. - Article Id: 70. - 23 p. DOI: $10.3390 / r s 8010070$.

4. MuLoG, or How to Apply Gaussian Denoisers to Multi-Channel SAR Speckle Reduction? [Text] / C.A. Deledalle, L. Denis, S. Tabti, F. Tupin // IEEE Transactions on Image Processing. - 2017. - Vol. 26. P. 4389-4403. DOI: 10.1109/TIP.2017.2713946.

5. Zhong, P. Multiple-Spectral-Band CRFs for Denoising Junk Bands of Hyperspectral Imagery [Text] / P. Zhong, R. Wang //IEEE Transactions on Geoscience and Remote Sensing. - 2013. - Vol. 51. - P. 2260-2275. DOI: 10.1109/TGRS.2012.2209656.

6. van Zyl Marais, I. Onboard image quality assessment for a small low earth orbit satellite [Text] / I. van Zyl Marais, W. H. Steyn, J. A. du Preez.// Proceedings of the 7th IAA Symposium on Small Satellites for Earth Observation. - Germany, 2009. - $7 p$. 
Характеристики точності комбінованої метрики якості

\begin{tabular}{|c|c|c|c|c|c|c|c|}
\hline \multirow{2}{*}{$\begin{array}{l}\text { № } \\
3 / \Pi\end{array}$} & \multirow{2}{*}{ Конфігурація ШНМ } & \multicolumn{3}{|c|}{ Найкраща ШНМ } & \multicolumn{3}{|c|}{5 найкращих результатів } \\
\hline & & SROCC & RMSE & PCC & SROCC & RMSE & PCC \\
\hline 1 & $\begin{array}{l}\text { Lasso (N>60), } 11 \text { входів, } 2 \text { шари (11/11 } \\
\text { нейронів) }\end{array}$ & 0,968 & 0,287 & 0,971 & 0,966 & 0,292 & 0,97 \\
\hline 2 & $\begin{array}{l}\text { Lasso (N>50), } 16 \text { входів, } 2 \text { шари (16/16 } \\
\text { нейронів) }\end{array}$ & 0,970 & 0,27 & 0,974 & 0,967 & 0,286 & 0,971 \\
\hline 3 & $\begin{array}{l}\text { Lasso (N>40), } 24 \text { входів, } 2 \text { шари ( } 24 / 24 \\
\text { нейронів) }\end{array}$ & 0,971 & 0,26 & 0,976 & 0,969 & 0,27 & 0,974 \\
\hline 6 & $\begin{array}{l}\text { Lasso (N>50), } 16 \text { входів, } 2 \text { шари ( } 16 / 8 \\
\text { нейронів) }\end{array}$ & 0,967 & 0,284 & 0,971 & 0,966 & 0,289 & 0,970 \\
\hline 8 & $\begin{array}{l}\text { Lasso (N>50), } 16 \text { входів, } 3 \text { шари } \\
\text { (16/16/16 нейронів) }\end{array}$ & 0,967 & 0,292 & 0,97 & 0,965 & 0,298 & 0,968 \\
\hline 9 & $\begin{array}{l}\text { Lasso (N>50), } 16 \text { входів, 3шари (16/8/4 } \\
\text { нейронів) }\end{array}$ & 0,968 & 0,285 & 0,971 & 0,967 & 0,284 & 0,971 \\
\hline
\end{tabular}

7. Accurate estimation of motion blur parameters in noisy remote sensing image [Text] / X. Shi, L. Wang, X. Shao, H. Wang, Z. Tao // Proceedings of the SPIE Sensing Technology + Applications. - Baltimore, United States, 2015. - 10 p. DOI: 10.1117/12.2176893.

8. Enhancement of Component Images of Multispectral Data by Denoising with Reference [Text] / S. Abramov, M. Uss, V. Lukin, B. Vozel, K. Chehdi, K. Egiazarian // Remote Sensing. - 2019. - Vol. 11, iss. 6. - Article Id: 611. - 16 p. DOI: 10.3390/rs11060611.

9. Dellepiane, S.G. Quality Assessment of Despeckled SAR Images [Text] / S. G. Dellepiane, E. Angiati // IEEE Journal of Selected Topics in Applied Earth Observations and Remote Sensing. - 2014. - Vol. 7. - P. 691707. DOI: 10.1109/JSTARS.2013.2279501.

10. Lin, W. Perceptual visual quality metrics: A survey [Text] / W. Lin, C. C. Jay Kuo // Journal of Visual Communication and Image Representation. - 2011. - Vol. 22, No. 4. - P. 297-312. DOI: 10.1016/j.jvcir.2011.01. 005 .

11. Analysis of classification accuracy for pre-filtered multichannel remote sensing data [Text] / V. Lukin, S. Abramov, S. Krivenko, A. Kurekin, O. Pogrebnyak // Expert Systems with Applications. - 2013. - Vol. 40. - P. 6400-6411. DOI: 10.1016/j.eswa.2013.05.061.

12. Aswathy, C. Hyperspectral Image Denoising Using Low Pass Sparse Banded Filter Matrix for Improved Sparsity Based Classification [Text] / C. Aswathy, V. Sowmya, K. P. Soman // Procedia Computer Science. - 2015. - Vol. 58. - P. 26-33. DOI: 10.1016/j.procs.2015.08.005.

13. Yang, K. Optimized-SSIM Based Quantization in Optical Remote Sensing Image Compression [Text] / $K$. Yang, H. Jiang // Proceedings of the 2011 Sixth International Conference on Image and Graphics. - China, 2011. - P. 117-122. DOI: 10.1109/ICIG.2011.38.

14. A Method for the Evaluation of Image Quality According to the Recognition Effectiveness of Objects in the Optical Remote Sensing Image Using Machine Learning Algorithm [Text] / T. Yuan, X. Zheng, X. Hu,
W. Zhou, W. Wang // PLoS ONE. - 2014. - Vol. 9(1) - 8 p. DOI: 10.1371/journal.pone.0086528.

15. Image matching using structural similarity and geometric constraint approaches on remote sensing images [Text] / J. Guo, F. Yang, H. Tan, J. Wang, Z. Liu // Journal of Applied Remote Sensing. - 2016. - Vol. 10, iss. 4. - Article Id: 045007. - 12 p. DOI: 10.1117/1.JRS. 10.045007 .

16. Chandler, D. M. Seven Challenges in Image Quality Assessment: Past, Present, and Future Research [Text] / D. M. Chandler // Signal Processing. - 2013. P. 1-53. DOI: 10.1155/2013/905685.

17. Image database TID2013: Peculiarities, results and perspectives [Text] / N. Ponomarenko, L. Jin, O. Ieremeiev, V. Lukin, K. Egiazarian, J. Astola, B. Vozel, K. Chehdi, M. Carli, et al. // Signal Processing: Image Communication. - 2015. - Vol. 30. - P. 57-77. DOI: 10.1016/j.image.2014.10.009.

18. Lin, H. KADID-10k: A Large-scale Artificially Distorted IQA Database [Text] / H. Lin, V. Hosu, D. Saupe // Proceedings of the 2019 Eleventh International Conference on Quality of Multimedia Experience (QoMEX). - Germany, 2019. - P. 1-3. DOI: 10.1109/QoMEX.2019.8743252.

19. Sun, W. MDID: A multiply distorted image database for image quality assessment [Text] / W. Sun, F. Zhou, Q. Liao // Pattern Recognit. - 2017. - Vol. 61. P. 153-168. DOI: 10.1016/j.patcog.2016.07.033.

20. Robust linearized combined metrics of image visual quality [Text] / O. Ieremeiev, V. Lukin, N. Ponomarenko, K. Egiazarian // Electronic Imaging, Image Processing: Algorithms and Systems XVI. - 2018. - 6 p. DOI: 10.2352/ISSN.2470-1173.2018.13.IPAS-260.

21. Okarma, K. Combined Full-Reference Image Quality Metric Linearly Correlated with Subjective Assessment [Text] / K. Okarma // Artificial Intelligence and Soft Computing; Lecture Notes in Computer Science. 2010. - Vol. 6113. - P. 539-546. DOI: 10.1007/978-3642-13208-7_67. 
22. Combining full-reference image visual quality metrics by neural network [Text] / V. V. Lukin, N. N. Ponomarenko, O. I. Ieremeiev, K. O. Egiazarian, J. Astola // SPIE/IS\&T Electronic Imaging. - United States, 2015. - Vol. 9394. - 6 p. DOI: 10.1117/12.2085465.

23. Deep Neural Networks for No-Reference and Full-Reference Image Quality Assessment [Text] / S. Bosse, D. Maniry, K.-R. Muller, T. Wiegand, W. Samek // IEEE Transactions on Image Processing. 2018. - Vol. 27. - P. 206-219. DOI: 10.1109/TIP.2017. 2760518.

24. Lossy Compression of Remote Sensing Images with Controllable Distortions [Text] / V. Lukin, A. Zemliachenko, S. Krivenko, B. Vozel, K. Chehdi // Satellite Information Classification and Interpretation. - 2019. $17 p$.

25. Ieremeiev, $O$. List of the full-reference metrics [Електронний ресурс] / O. Iеrетеіеv. - Режим доcmyny: https://github.com/OlegIeremeiev/IQA/wiki/ MRRS2020. - 5.10.2020.

26. Neural network-based full-reference image quality assessment [Text] / S. Bosse, D. Maniry, K.R. Muller, T. Wiegand, W. Samek // In Proceedings of the 2016 Picture Coding Symposium (PCS). - Germany, 2016. - P. 1-5. DOI: 10.1109/PCS.2016.7906376.

27. Athar, S. A Comprehensive Performance Evaluation of Image Quality Assessment Algorithms [Text] / S. Athar, Z. Wang// IEEE Transactions on Image Processing. - 2019. - Vol. 7 - P. 140030-140070. DOI: 10.1109/ACCESS.2019.2943319.

28. Tibshirani, R. Regression Shrinkage and Selection Via the Lasso [Text] / R. Tibshirani // Journal of the Royal Statistical Society. Series B (Methodological). 1996. - Vol. 58, No. 1. - P. 267-288. DOI: 10.1111/j.2517-6161.1996.tb02080.x.

\section{References}

1. Schowengerdt, R. A. Remote sensing, models, and methods for image processing, 3rd ed. Academic Press, Burlington Publ., MA, 2007. 560 p.

2. Khorram, S., van der Wiele, C. F., Koch, F. H., Nelson, S. A. C., Potts, M. D. Future Trends in Remote Sensing. Principles of Applied Remote Sensing, Springer International Publishing: Cham, 2016, pp. 277-285.

3. Joshi, N., Baumann, M., Ehammer, A., Fensholt, R., Grogan, K., Hostert, P., Jepsen, M., Kuemmerle, T., Meyfroidt, P., Mitchard, E. A Review of the Application of Optical and Radar Remote Sensing Data Fusion to Land Use Mapping and Monitoring. Remote Sensing, 2016, vol. 8, no. 1, article id: 70.23 p. DOI: $10.3390 / \mathrm{rs} 8010070$.

4. Deledalle, C.-A., Denis, L., Tabti, S., Tupin, F. MuLoG, or How to Apply Gaussian Denoisers to MultiChannel SAR Speckle Reduction? IEEE Transactions on Image Processing, 2017, vol. 26, pp. 4389-4403. DOI: 10.1109/TIP.2017.2713946.

5. Zhong, P., Wang, R. Multiple-Spectral-Band CRFs for Denoising Junk Bands of Hyperspectral Imagery. IEEE Transactions on Geoscience and Remote
Sensing, 2013, vol. 51, pp. 2260-2275. DOI: 10.1109/TGRS.2012.2209656.

6. van Zyl Marais, I., Steyn, W. H., du Preez, J. A. Onboard image quality assessment for a small low earth orbit satellite. Proceedings of the 7th IAA Symposium on Small Satellites for Earth Observation, 2009. 7 p.

7. Shi, X., Wang, L., Shao, X., Wang, H., Tao, Z. Accurate estimation of motion blur parameters in noisy remote sensing image. Proceedings of the SPIE Sensing Technology + Applications, Baltimore, 2015. 10 p. DOI: 10.1117/12.2176893.

8. Abramov, S., Uss, M., Lukin, V., Vozel, B., Chehdi, K., Egiazarian, K. Enhancement of Component Images of Multispectral Data by Denoising with Reference. Remote Sensing, 2019, vol. 11, iss. 6, article id: 611. 16 p. DOI: $10.3390 /$ rs11060611.

9. Dellepiane, S. G., Angiati, E. Quality Assessment of Despeckled SAR Images. IEEE Journal of Selected Topics in Applied Earth Observations and Remote Sensing, 2014, vol. 7, pp.691-707. DOI: 10.1109/JSTARS.2013.2279501.

10. Lin, W., Jay Kuo, C. C. Perceptual visual quality metrics: A survey. Journal of Visual Communication and Image Representation, 2011, vol. 22, no. 4, pp. 297-312. DOI: 10.1016/j.jvcir.2011.01.005.

11. Lukin, V., Abramov, S., Krivenko, S., Kurekin, A., Pogrebnyak, O. Analysis of classification accuracy for pre-filtered multichannel remote sensing data. Expert Systems with Applications, 2013, vol. 40, pp. 6400-6411. DOI: 10.1016/j.eswa.2013.05.061.

12. Aswathy, C., Sowmya, V., Soman, K.P. Hyperspectral Image Denoising Using Low Pass Sparse Banded Filter Matrix for Improved Sparsity Based Classification. Procedia Comput. Sci. 2015, vol. 58, pp. 2633. DOI: 10.1016/j.procs.2015.08.005.

13. Yang, K., Jiang, H. Optimized-SSIM Based Quantization in Optical Remote Sensing Image Compression. Proceedings of the 2011 Sixth International Conference on Image and Graphics, Hefei, Anhui, China, 2011, pp. 117-122, DOI: 10.1109/ICIG.2011.38.

14. Yuan, T., Zheng, X., Hu, X., Zhou, W., Wang, W. A Method for the Evaluation of Image Quality According to the Recognition Effectiveness of Objects in the Optical Remote Sensing Image Using Machine Learning Algorithm. PLoS ONE, 2014, vol. 9(1). 8 p. DOI: 10.1371/journal.pone.0086528.

15. Guo, J., Yang, F., Tan, H., Wang, J., Liu, Z. Image matching using structural similarity and geometric constraint approaches on remote sensing images. J. Appl. Remote Sens., 2016, vol. 10, iss. 4, article id: 045007. 12 p. DOI: $10.1117 / 1 . J R S .10 .045007$.

16. Chandler, D. M. Seven Challenges in Image Quality Assessment: Past, Present, and Future Research. Signal Process., 2013, pp. 1-53. DOI: $10.1155 / 2013 / 905685$.

17. Ponomarenko, N., Jin, L., Ieremeiev, O., Lukin, V., Egiazarian, K., Astola, J., Vozel, B., Chehdi, K., Carli, M., Battisti, F. Image database TID2013: Peculiarities, results and perspectives. Signal Processing: Image 
Communications, 2015, vol. 30, pp. 57-77. DOI: 10.1016/j.image.2014.10.009.

18. Lin, H., Hosu, V., Saupe, D. KADID-10k: A Large-scale Artificially Distorted IQA Database. Proceedings of the 2019 Eleventh International Conference on Quality of Multimedia Experience (QoMEX), Berlin, 2019, pp. 1-3. DOI: 10.1109/QoMEX.2019.8743252.

19. Sun, W., Zhou, F., Liao, Q. MDID: A multiply distorted image database for image quality assessment. Pattern Recognitition, 2017, vol. 61, pp. 153-168. DOI: 10.1016/j.patcog.2016.07.033.

20. Ieremeiev, O., Lukin, V., Ponomarenko, N., Egiazarian, K. Robust linearized combined metrics of image visual quality. Electronic Imaging, Image Processing: Algorithms and Systems XVI, 2018, pp. 260-1260-6. DOI: 10.2352/ISSN.2470-1173.2018.13.IPAS260.

21. Okarma, K. Combined Full-Reference Image Quality Metric Linearly Correlated with Subjective Assessment. In Artificial Intelligence and Soft Computing. Lecture Notes in Computer Science, 2010, vol. 6113, pp. 539-546. DOI: 10.1007/978-3-642-13208-7_67.

22. Lukin, V. V., Ponomarenko, N. N., Ieremeiev, O. I., Egiazarian, K. O., Astola, J. Combining full-reference image visual quality metrics by neural network. SPIE/IS\&T Electronic Imaging, 2015, vol. 9394. 6 p. DOI: $10.1117 / 12.2085465$.
23. Bosse, S., Maniry, D., Muller, K.-R., Wiegand, T., Samek, W. Deep Neural Networks for No-Reference and Full-Reference Image Quality Assessment. IEEE Transactions on Image Processing, 2018, vol. 27, pp. 206-219. DOI: 10.1109/TIP.2017.2760518.

24. Lukin, V., Zemliachenko, A., Krivenko, S., Vozel, B., Chehdi, K. Lossy Compression of Remote Sensing Images with Controllable Distortions. Satellite Information Classification and Interpretation, IntechOpen, 2019. $17 \mathrm{p}$.

25. Ieremeiev, O. List of the full-reference metrics. Available at: https://github.com/OlegIeremeiev/IQA/ wiki/MRRS2020. (accessed 5.10.2020).

26. Bosse, S., Maniry, D., Muller, K.-R., Wiegand, T., Samek, W. Neural network-based full-reference image quality assessment. Proceedings of the 2016 Picture Coding Symposium (PCS), Nuremberg, 2016, pp. 1-5. DOI: 10.1109/PCS.2016.7906376.

27. Athar, S., Wang, Z. A Comprehensive Performance Evaluation of Image Quality Assessment Algorithms. IEEE Transactions on Image Processing, 2019, vol. 7, pp. 140030-140070. DOI: 10.1109/ACCESS.2019.2943319.

28. Tibshirani, R. Regression Shrinkage and Selection Via the Lasso. Journal of the Royal Statistical Society. Series B (Methodological), 1996, vol. 58, pp. 267288. DOI: $10.1111 /$ j.2517-6161.1996.tb02080.x.

Поступила в редакциию 12.10.2020, рассмотрена на редколлегии 16.11.2020

\section{КОМБИНИРОВАННАЯ МЕТРИКА ВИЗУАЛЬНОГО КАЧЕСТВА ИЗОБРАЖЕНИЙ ДИСТАНЦИОННОГО ЗОНДИРОВАНИЯ НА ОСНОВЕ НЕЙРОНЫХ СЕТЕЙ}

\section{О. И. Еремеев, В. В. Лукин, К. Окарма}

Широкое распространение изображений дистанционного зондирования (ДЗ) Земли в различных прикладных областях делает актуальной задачу обеспечения высокого качества таких изображений, что требуется для выявления необходимой информации. Сложность систем и влияние различных физических процессов обусловливают наличие значительного количества помех, приводящих к искажению изображений и возможной потери информации. Применение методов обработки, что должны снизить влияние таких факторов, требует контроля их работы, для чего используют количественные показатели визуального качества. В статье рассматривается задача создания комбинированной метрики визуального качества на основе искусственной нейронной сети (ИНС), что обеспечит высокую точность оценки визуального качества и стабильность работы на помехах, характерных для ДЗ. Рассмотрена проблема анализа помех ДЗ и предложен подход использования базы тестовых изображений TID2013 для верификации на типичных для Д3 искажениях. Проведен анализ современных метрик визуального качества и их пригодность для оценки таких изображений. По его результатам определено, что лучшие метрики обеспечивают точность оценки качества для задач Д3 на уровне 0,93 за ранговой корреляцией Спирмена с субъективными оценками базы TID2013. Взаимное применение существующих метрик качества позволяет нивелировать недостатки каждой из них и повысить общую эффективность, поэтому в статье рассмотрены проблемы и определены требования по созданию комбинированной метрики с привлечением нейронной сети. Предложен метод ограничения количества задействованных метрик качества с использованием регуляризации Lasso, что позволяет определить наиболее информативные признаки (метрики качества) и упростить процедуру выбора и уменьшения их количества. Проведено исследование влияния критерия выбора метрик и количества на точность работы комбинированной метрики. Также проанализировано влияние структуры нейронной сети, количества скрытых слоев и количества нейронов в них. На основе полученных результатов выбрано лучшую реализацию ИНС, которая при привлечении 16 метрик визуального качества позволяет достигать точности оценки визуального качества в 0,97 по корреляции Спирмена с субъективными оценками базы TID2013.

Ключевые слова: метрика визуального качества; нейронная сеть; обработка изображений; оценка качества изображений; база изображений. 


\section{COMBINED VISUAL QUALITY METRIC OF REMOTE SENSING IMAGES BASED ON NEURAL NETWORK \\ O. Ieremeiev, V. Lukin, K. Okarma}

The wide distribution of images of remote sensing (RS) of the Earth in various application areas makes it important to ensure the high quality of such images, which is important to identify necessary information. The complexity of the systems and the impact of various physical processes cause a significant number of distortions that lead to image corruption and possible loss of information. The use of processing methods that should reduce the impact of such factors requires control of their work, which uses quantitative indicators of visual quality. The article considers the task of creating a combined visual quality metric based on an artificial neural network (ANN), which provides high accuracy of visual quality assessment and stability of work on the noise characteristic of the RS. The problem of analysis of RS distortions is considered and the approach of using the database of test images TID2013 for verification on typical RS distortions is offered. The analysis of well-known visual quality metrics and their suitability for the estimation of such images is carried out. According to its results, it was determined that the best metrics provide the accuracy of image quality assessment for RS tasks at the level of 0.93 according to Spearman's rank-order correlation coefficient with subjective estimates of the TID2013 image database. The joint application of existing quality metrics allows eliminating the shortcomings of each of them and increasing the overall efficiency, so the article considers the problems and defines the requirements for creating a combined metric involving a neural network. A method of limiting the number of involved quality metrics with the involvement of Lasso regularization is proposed, which allows determining the most informative features (quality metrics) and simplifying the procedure of selection and reduction of their number. A study was conducted on the influence of the metric selection criterion and quantity on the accuracy of the combined metric. The influence of the structure of the neural network, the number of hidden layers, and the number of neurons in them are also analyzed. Based on the obtained results, the best implementation of ANN was selected, which with the involvement of 16 visual quality metrics allows achieving the accuracy of visual quality assessment at 0.97 according to Spearman's correlation with subjective estimates of the TID2013 database.

Keywords: visual quality metrics; neural network; image processing; image quality assessment; image database.

Еремеев Олег Игоревич - канд. техн. наук, доц. каф. информационно-коммуникационных технологий им. А. А. Зеленского, Национальный аэрокосмический университет им. Н. Е. Жуковского «Харьковский авиационный институт», Харьков, Украина.

Лукин Владимир Васильевич - д-р техн. наук, проф., зав. каф. информационно-коммуникационных технологий им. А. А. Зеленского, Национальный аэрокосмический университет им. Н. Е. Жуковского «Харьковский авиационный институт», Харьков, Украина.

Криштоф Окарма - д-р техн. наук, проф., декан факультета электротехники, заведующий кафедрой обработки сигналов и мультимедийной инженерии, Западно-Поморский технологический университет, Щецин, Польша.

Oleg Ieremeiev - PhD of Technical Science, Associate Professor of Department of Information-communication technologies named after O.O. Zelensky, National Aerospace University "Kharkov Aviation Institute", Kharkov, Ukraine, e-mail: o.ieremeiev@khai.edu,

ORCID: 0000-0001-7865-0570, Scopus Author ID: 37121982400, Researcher ID: T-1106-2017

https://scholar.google.com/citations?user=ZkhysAYAAAAJ\&hl.

Vladimir Lukin - Doctor of Technical Science, Professor, Head of Department of Information-communication technologies named after O. O. Zelensky, National Aerospace University "Kharkov Aviation Institute", Kharkov, Ukraine, e-mail: lukin@ai.kharkov.com,

ORCID: 0000-0002-1443-9685, Scopus Author ID: 7102438809, Researcher ID: A-8219-2014,

https://scholar.google.com.ua/citations?user=XI9iavwAAAAJ\&hl.

Krzysztof Okarma - Doctor of Technical Science, Professor (Associate), Dean of Faculty of Electrical Engineering, Head of Department of Signal Processing and Multimedia Engineering, West Pomeranian University of Technology, Szczecin, Poland, e-mail: okarma@ zut.edu.pl,

ORCID: 0000-0002-6721-3241, Scopus Author ID: 15063220000, Researcher ID: B-8792-2011,

https://scholar.google.com/citations?user=Lmnuuv4AAAAJ\&hl. 